\title{
Presynaptic dopaminergic function is largely unaltered in mesolimbic and mesostriatal terminals of adult rats that were prenatally exposed to cocaine
}

\author{
Paul E.M. Phillips ${ }^{a, b}$, Josephine M. Johns ${ }^{c, d}$, Deborah A. Lubin ${ }^{d}$, Evgeny A. Budygin ${ }^{a, b, 1}$, \\ Raul R. Gainetdinove ${ }^{e}$, Jeffery A. Lieberman ${ }^{b, c}$, and R. Mark Wightman ${ }^{a, b},{ }^{,}$ \\ aDepartment of Chemistry, Venable Hall CB3290, University of North Carolina, Chapel Hill, NC \\ 27599-3290, USA \\ bNeuroscience Center, University of North Carolina, Chapel Hill, NC 27599, USA \\ 'Department of Psychiatry, University of North Carolina, Chapel Hill, NC 27599, USA \\ dDepartment of Psychology, University of North Carolina, Chapel Hill, NC 27599, USA \\ eDepartment of Cell Biology, Duke University, Durham, NC 27710, USA
}

\begin{abstract}
Fast-scan cyclic voltammetry in brain slices and postmortem tissue content assessment were used to evaluate presynaptic dopaminergic function in the caudate putamen and nucleus accumbens of adult male rats (180+ days old) that were prenatally treated with either cocaine or saline.

Experiments were carried out to test whether there were differences in dopamine release, reuptake, autoreceptor function or the tissue levels of dopamine and its metabolites between cocaine- and saline-exposed rats. We report that presynaptic dopaminergic function remains largely intact in adult rats that were prenatally exposed to cocaine. The ability of terminals in the caudate putamen and nucleus accumbens to release and regulate dopamine is unaltered by prenatal cocaine exposure. However the tissue content of dopamine in the caudate putamen was decreased, representing a diminution in the dopamine storage pool. We conclude, therefore, that behavioral changes that have previously been observed in rats that were prenatally exposed to cocaine are not mediated through alteration of presynaptic dopaminergic mechanisms in these brain regions.
\end{abstract}

\section{Keywords}

Fast-scan cyclic voltammetry; Brain slice; Release; Uptake; Autoinhibition

\section{Introduction}

There have been a number of reports of changes in dopaminergic function in young offspring that were exposed to cocaine in utero $[3,6,15,16,23]$. Behavioral abnormalities have been correlated with some of these changes [6]. However, dopaminergic function in adults that were prenatally exposed to cocaine has been less extensively studied. This group is of particular interest because they express altered social and aggressive behavior $[10,11,24,34]$ relative to animals prenatally exposed to saline. In particular, adult male rats

\footnotetext{
(C) 2002 Elsevier Science B.V. All rights reserved.

Corresponding author. Tel.: +1-919-962-1472; fax: +1-919-962-2388.rmw@unc.edu (R.M. Wightman).

${ }^{1}$ Present address: Department of Physiology and Pharmacology, Wake Forest University School of Medicine, Winston-Salem, NC 27106, USA.
} 
of 180 days old or more show increased aggression and were somewhat more neophobic (reluctant to explore a novel environment) than saline-exposed controls [10].

The etiology of these effects remains unclear. Exposure to cocaine in pregnant dams induces uterine ischemia [20] which may disrupt embryonic development of dopaminergic neurons. In addition, cocaine has a number of other pharmacological properties that may affect the fetus directly. These include a local anesthetic action [4] and competitive antagonism of the plasma membrane transporters of (highest to lowest potency) serotonin, dopamine and norepinephrine [29]. In particular, blockade of the dopamine transporter by cocaine in utero may affect development of dopaminergic mechanisms. Indeed, when the dopamine transporter is not present during development (and beyond) in knockout mice, presynaptic dopaminergic function is grossly altered: not surprisingly dopamine clearance is vastly reduced, but dopamine content and release are also markedly decreased, and synthesis and metabolism are increased [12].

Presynaptic function strongly influences dopaminergic neurotransmission. Dopamine is synthesized from tyrosine in the cytosol of dopaminergic terminals. It can then be packaged into small synaptic vesicles by the vesicular monoamine transporter or metabolized to 3,4dihyrox-yphenylacetic acid (DOPAC) and homovanillic acid (HVA) [14]. Some vesicles bind to the cytoskeleton by actin filaments [28] to form a storage pool which can be subsequently mobilized again by phosphorylation [32]. Mobile vesicles can dock to release sites where they can be undocked to be mobile once again in the cytosol or their contents can be released into the extracellular compartment by exocytosis [25]. Once dopamine enters the extracellular space, it can interact with receptors until it is eventually removed by the dopamine transporter [2]. If presynaptic D2-like terminal autoreceptors are activated [27], further synthesis and secretion of dopamine is inhibited. The integration of all of these processes ultimately determines the availability of dopamine for release. In addition, the dopamine transporter regulates the time that it remains in the extracellular space.

The present study addresses whether there are long-lasting changes in presynaptic dopaminergic function following prenatal exposure to cocaine that are present in adults and could potentially contribute to behavioral abnormalities. This was assessed using fast-scan cyclic voltammetry in brain slices and postmortem tissue content assessment from adult male rats that had been prenatally exposed to cocaine or saline.

\section{Methods}

\subsection{Animals}

Virgin female (225-250 g) Sprague-Dawley rats (Charles River, Raleigh, NC, USA) were group housed (rats per cage) during a two week habituation period. Rooms were on a 12-h timed reverse light/dark cycle and animals had free access to rat chow (Purina) and water. Females were bred and the morning a sperm plug was found was designated as gestational day 0 . Sperm positive females were removed and randomly assigned to one of two treatment groups or as a surrogate and housed singly in plastic rat cages. The treatment groups received subcutaneous injections of either $15 \mathrm{mg} / \mathrm{kg}$ of cocaine- $\mathrm{HCl}$ (Sigma, St. Louis, MO, USA) in a normal $(0.9 \%)$ saline solution or an equal volume of normal saline twice daily at approximately 09:00 and 16:00 $\mathrm{h}$ from gestational days 1-20. Surrogates received no treatment. Rat dams remained on the reverse light cycle for 8 days and were then housed in a room with a normal 12-h light / dark cycle which results in most dams delivering in the afternoon rather than the early morning (02:00-03:00 h). This procedure has been used in several behavioral experiments and is more practical since we foster litters as soon as birth is completed [21,22]. 
Cocaine, saline and surrogate dams were fed ad libitum during pregnancy. Treatment dams were weighed daily (surrogate dams were weighed every 3 days). Daily weight gain and any unusual observations were recorded. Upon delivery, litters were weighed, and separated into same sex litters of 10 male pups, one pup from each litter. Only one pup from any litter was used in any group of experiments to control for litter effects. Pups were immediately given to a surrogate dam that had delivered within $24 \mathrm{~h}$ of the cocaine or saline-treated dams. Pups are transferred to the surrogate dams because we know that cocaine treatment can alter maternal behavior towards the pups and we can control for differences resulting from abnormal maternal behavior by cocaine-treated dams by fostering all pups to surrogates. In this way biochemical differences can be assumed to be the result of the prenatal exposure and not maternal behavioral differences.

\subsection{Brain slices}

Brain slices from adult progeny (postnatal day 180+) were prepared and maintained as previously described [18]. Briefly, rats were sacrificed by decapitation and the brains rapidly removed and cooled in ice-cold, pre-oxygenated $\left(95 \% \mathrm{O}_{2} / 5 \% \mathrm{CO}_{2}\right)$ artificial cerebrospinal fluid. The tissue was sectioned into $400-\mu \mathrm{m}$ thick coronal slices containing the caudate putamen or the nucleus accumbens, using a vibrotome (Vibroslice NVSL; World Precision Instruments, Sarasota, FL, USA). Slices were kept in a reservoir of oxygenated artificial cerebrospinal fluid at room temperature for up to $6 \mathrm{~h}$ until required. Thirty minutes before each experiment, a brain slice was transferred to a 'Scottish-type' submersion recording chamber [1], superfused at $1 \mathrm{ml} / \mathrm{min}$ with $34^{\circ} \mathrm{C}$ oxygenated artificial cerebrospinal fluid, and allowed to equilibrate. The artificial cerebrospinal fluid consisted of (in $\mathrm{mM}$ ): $\mathrm{NaCl}$ (126), $\mathrm{KCl}$ (2.5), $\mathrm{NaH}_{2} \mathrm{PO}_{4}$ (1.2), $\mathrm{CaCl}_{2}$ (2.4), $\mathrm{MgCl}_{2}$ (1.2), $\mathrm{NaHCO}_{3}$ (25), glucose (11), HEPES (20) and was pH adjusted to 7.4.

Recordings were made either in the dorsolateral part of the caudate putamen or in the core of the nucleus accumbens. A cylindrical carbon fiber microelectrode ( $7 \mu \mathrm{m}$ diameter, $\sim 100 \mu \mathrm{m}$ long) was inserted into the slice and a bipolar stimulating electrode (Plastics One, Roanoke, VA, USA) was placed on the surface of the brain slice $200 \mu \mathrm{m}$ away. Extracellular dopamine was monitored at the carbon fiber microelectrode every $100 \mathrm{~ms}$ using fast-scan cyclic voltammetry [17] by applying a triangular waveform $(-0.4$ to $+1.0 \mathrm{~V}$ vs. $\mathrm{Ag} / \mathrm{AgCl}$, $300 \mathrm{~V} / \mathrm{s}$ ) using a biopotentiostat (EI400, Cypress Systems, Lawrence, KS, USA). Data were digitized (National Instruments, Austin, TX, USA) and stored to a computer. Dopamine release was evoked by single electrical pulses ( $\pm 300 \mu \mathrm{A}, 2 \mathrm{~ms} / \mathrm{phase})$ applied across the stimulating electrode every $5 \mathrm{~min}$. In some experiments, 20-pulse $(50 \mathrm{~Hz})$ stimulation trains were also used to elicit dopamine release. In experiments where the absolute concentration of dopamine was reported, three recording sites were used per slice to get a better estimate of the population of dopamine release. So as not to introduce bias, the first three implantations into the slice were used regardless of the release they yielded. In other experiments, after a 30-min (six stimulation) stable baseline was achieved, cocaine (1 and 10 $\mu \mathrm{M}$; Sigma, St. Louis, MO, USA) or quinpirole (0.001, 0.01, 0.1, 1 and $10 \mu \mathrm{M}$; Sigma) were applied cumulatively ( 30 min per concentration) to the brain slice via the superfusant.

To assess the effects of these acute cocaine experiments, evoked levels of extracellular dopamine were modeled as a balance between release and uptake [33]. The change in dopamine concentration with respect to time was estimated by:

$$
\mathrm{d}[\mathrm{DA}] / \mathrm{d} t=[\mathrm{DA}]_{\mathrm{p}}-V_{\max } /\left(K_{\mathrm{m}} /[\mathrm{DA}]+1\right)
$$


where $[D A]$ is the brain extracellular concentration of dopamine, $[\mathrm{DA}]_{\mathrm{p}}$ is the change in concentration of dopamine at the electrode produced by each stimulus pulse, and $V_{\max }$ and $K_{\mathrm{m}}$ are Michaelis-Menten rate constants for dopamine uptake.

\subsection{Content studies}

Animals were sacrificed by decapitation, and their brains rapidly removed. The caudate putamen, nucleus accumbens and prefrontal cortex were dissected out and homogenized in $0.1 \mathrm{M} \mathrm{HClO}_{4}$ containing $100 \mathrm{ng} / \mathrm{ml} \mathrm{3,4-dihydroxybenzylamine} \mathrm{as} \mathrm{an} \mathrm{internal} \mathrm{standard.}$ Homogenates were centrifuged for $10 \mathrm{~min}$ at $10000 \times g$. Supernatants were filtered through $0.22-\mathrm{mm}$ filters and analyzed using high performance liquid chromatography with electrochemical detection. Samples $(20 \mu \mathrm{l})$ were separated on a reverse-phase column $\left(\mathrm{C}_{18}\right.$, $100 \times 4.60 \mathrm{~mm}$, Ultremex) with a mobile phase consisting of $50 \mathrm{mM}$ monobasic sodium phosphate, $0.2 \mathrm{mM}$ octyl sodium sulfate, $0.1 \mathrm{mM}$ EDTA, $10 \mathrm{mM} \mathrm{NaCl}$ and $10 \%$ methanol (pH 2.6) at a flow rate of $1 \mathrm{ml} / \mathrm{min}$. Dopamine, DOPAC, HVA, norepinephrine, serotonin and 5-hyroxyindolacetic acid were detected by constant-potential amperometry $(+0.65 \mathrm{~V}$ vs. $\mathrm{Ag} / \mathrm{AgCl}$ ) at a glassy carbon electrode (BioAnalytical Systems).

\subsection{Statistical analysis}

All statistical analyses and sigmoid curve fitting were carried out using Prism ${ }^{\circledR}(\mathrm{GraphPad}$ Software, San Diego, CA, USA). Tissue content data were compared between prenatal saline and prenatal cocaine-treated groups using unpaired $t$-tests. Other data were evaluated by two-way analysis of variance.

\section{Results}

\subsection{Gestational effects}

There were no significant differences between cocaine-treated and control dams on measures of dam weight gain, litter weight, number of male and female pups or number of pups per litter.

\subsection{Electrically evoked dopamine release}

Electrical stimulation produced a transient increase in the extracellular dopamine concentration (Fig. 1A). The rising phase is reciprocally controlled by dopamine release and uptake, and the falling phase by uptake alone [33]. Consequently, the peak amplitude $\left([D A]_{\max }\right)$ is an index of the balance between release and uptake.

In dorsolateral caudate putamen, $[\mathrm{DA}]_{\max }$ following stimulation with a single electrical pulse was $1.31 \pm 0.20 \mu \mathrm{M}(n=12$ recording sites from four animals $)$ for prenatal saline and $1.06 \pm 0.22 \mu \mathrm{M}(n=18$ recording sites from six animals $)$ for prenatal cocaine-treated rats (mean \pm s.e.m.; Fig. 1B). For stimulation with twenty electrical pulses $(50 \mathrm{~Hz}),[\mathrm{DA}]_{\max }$ was approximately double that for a single pulse: $2.79 \pm 0.61 \mu \mathrm{M}(n=12$ recording sites from four animals) for prenatal saline and $2.34 \pm 0.49 \mu \mathrm{M}(n=12$ recording sites from four animals) for prenatal cocaine-treated rats (Fig. 1B). Statistical analysis (two-way analysis of variance) revealed a main effect of stimulation pulses $\left(F_{1,56}=10.91, P<0.01\right)$, but no effect of treatment $\left(F_{1,56}=0.70, P>0.05\right)$ or interaction between these $\left(F_{1,56}=0.05, P>0.05\right)$.

In the nucleus accumbens, $[\mathrm{DA}]_{\max }$ for a single electrical pulse was $0.29 \pm 0.08 \mu \mathrm{M}$ for prenatal saline and $0.28 \pm 0.05 \mu \mathrm{M}$ for prenatal cocaine-treated rats $(P>0.05 ; n=12$ recording sites from four animals; Fig. 1B) and about fourfold higher for twenty pulses: 1.18 $\pm 0.28 \mu \mathrm{M}$ for prenatal saline and $1.27 \pm 0.16 \mu \mathrm{M}$ for prenatal cocaine-treated rats $(n=12$ recording sites from four animals; Fig. 1B). There was a main effect of stimulation pulses 
$\left(F_{1,43}=34.43, P<0.0001\right)$, but no effect of treatment $\left(F_{1,43}=0.05, P>0.05\right)$ or interaction between these $\left(F_{1,43}=0.11, P>0.05\right)$.

\subsection{Acute cocaine challenge}

To test dopamine uptake following acute cocaine challenge, cocaine was applied to brain slices cumulatively at two concentrations $(1$ and $10 \mu \mathrm{M})$. In general, during application of 1 $\mu \mathrm{M}$ cocaine, there was an increase in the amplitude and duration of the extracellular dopamine response to stimulation, and at $10 \mu \mathrm{M}$ there was a further widening, but often a decrease in the amplitude (Fig. 2A). Cocaine's effects were further assessed by kinetic analysis of these responses.

For baseline data, responses could be fitted well when $K_{\mathrm{m}}$ was set to $0.16 \mu \mathrm{M}$ (Fig. 2B), and when $V_{\max }$ was set to $4 \mu \mathrm{M} / \mathrm{s}$ for the caudate putamen or $2 \mu \mathrm{M} / \mathrm{s}$ for the nucleus accumbens. In the caudate putamen, $[\mathrm{DA}]_{\mathrm{p}}$ was $1.68 \pm 0.13 \mu \mathrm{M}$ for prenatal saline and 1.78 $\pm 0.45 \mu \mathrm{M}$ for prenatal cocaine-treated rats (Fig. 2C). In the nucleus accumbens, it was 0.95 $\pm 0.10 \mu \mathrm{M}$ for prenatal saline and $0.85 \pm 0.07 \mu \mathrm{M}$ for prenatal cocaine-treated rats.

Cocaine's effect was best fitted to an increase in the apparent $K_{\mathrm{m}}$ without any change in $V_{\max }$, consistent with competitive antagonism of the dopamine transporter. In addition, $[D A]_{p}$ needed to be modified by a relatively small degree. In the caudate putamen, the apparent $K_{\mathrm{m}}$ increased more than 15 -fold with $1-\mu \mathrm{M}$ cocaine to $2.78 \pm 0.46 \mu \mathrm{M}$ in prenatal saline and $2.51 \pm 0.32 \mu \mathrm{M}$ in prenatal cocaine-treated rats (Fig. 2B). With $10-\mu \mathrm{M}$ cocaine, it continued to increase to more than 50 times the predrug value, reaching $10.50 \pm 1.94 \mu \mathrm{M}$ (prenatal saline) and $8.68 \pm 1.40 \mu \mathrm{M}$ (prenatal cocaine). Although this effect of acute cocaine was highly significant $\left(F_{2,9}=45.37, P<0.0001\right)$, there was no main effect of prenatal treatment $\left(F_{1,9}=0.77, P>0.05\right)$ nor was there an interaction $\left(F_{2,9}=0.46, P>\right.$ $0.05)$. This effect of cocaine was paralleled in the nucleus accumbens where the apparent $K_{\mathrm{m}}$ increased to to $2.40 \pm 0.55 \mu \mathrm{M}$ in prenatal saline and $1.75 \pm 0.30 \mu \mathrm{M}$ in prenatal cocainetreated rats for $1 \mu \mathrm{M}$ and to $10.05 \pm 2.74 \mu \mathrm{M}$ (prenatal saline) and $11.00 \pm 2.12 \mu \mathrm{M}$ (prenatal cocaine) for $10-\mu \mathrm{M}$ cocaine (Fig. $2 \mathrm{~B})$. Again, cocaine's effect was significant $\left(F_{2,9}\right.$ $=25.08, P<0.001)$ but prenatal treatment did not have a main effect $\left(F_{1,9}=0.01, P>0.05\right)$ or alter this response $\left(F_{2,9}=0.13, P>0.05\right)$. To fit the effect of $1-\mu \mathrm{M}$ cocaine, $[\mathrm{DA}]_{\mathrm{p}}$ was increased to $2.07 \pm 0.13 \mu \mathrm{M}$ in the caudate putamen and $1.15 \pm 0.17 \mu \mathrm{M}$ in the nucleus accumbens of prenatal saline rats, and to $2.10 \pm 0.37 \mu \mathrm{M}$ in the caudate putamen and $1.16 \pm$ $0.15 \mu \mathrm{M}$ in the nucleus accumbens of prenatal cocaine-treated rats (Fig. 2C). At 10- $\mu \mathrm{M}$ cocaine, $[\mathrm{DA}]_{\mathrm{p}}$ dropped below the predrug value to $1.13 \pm 0.16 \mu \mathrm{M}$ (prenatal saline) and $1.29 \pm 0.19 \mu \mathrm{M}$ (prenatal cocaine) in the caudate putamen and $0.50 \pm 0.11 \mu \mathrm{M}$ (prenatal saline) and $0.46 \pm 0.07 \mu \mathrm{M}$ (prenatal cocaine) in the nucleus accumbens. The effect of acute cocaine on $[\mathrm{DA}]_{\mathrm{p}}$ was significant $\left(F_{2,9}=8.65, P<0.01\right.$, caudate putamen; $F_{2,9}=16.54, P<$ 0.001 , nucleus accumbens), but once again, prenatal treatment had no effect $\left(F_{1,9}=0.13, P\right.$ $>0.05$, caudate putamen; $F_{1,9}=0.18, P>0.05$, nucleus accumbens) nor interacted with cocaine's effect $\left(F_{2,9}=0.04, P>0.05\right.$, caudate putamen; $F_{2,9}=0.11, P>0.05$, nucleus accumbens). The decrease of $[\mathrm{DA}]_{\mathrm{p}}$ (seen in both prenatal treatment groups) at the higher cocaine concentration has been observed previously [13]. This probably represents a progressive depletion of dopamine due to the inability for it to be taken back up into terminals while the dopamine transporter is blocked.

\subsection{Dopamine autoinhibition}

To test dopamine terminal autoreceptor function, the D2-like agonist, quinpirole, was applied to brain slices at cumulative concentrations (1-10 $000 \mathrm{nM})$. Quinpirole produced concentration-dependent inhibitions of $[\mathrm{DA}]_{\max }$ for single pulse electrical stimulation that could be fitted by a sigmoid curve when plotted as a semilog graph $\left(R^{2}=0.99\right.$; Fig. 3$)$. 
During curve-fitting Hill slopes were fixed to a standard slope factor (1.0). This was justified because if they were fitted, values of $1.15 \pm 0.15$ (prenatal saline) and $0.92 \pm 0.10$ (prenatal cocaine) in the caudate putamen and $0.99 \pm 0.03$ (prenatal saline) and $1.02 \pm 0.11$ (prenatal cocaine) in the nucleus accumbens were obtained. The bottom of the slopes (i.e. response for no quinpirole) were fixed to the pre-quinpirole value $(100 \%)$.

In dorsolateral caudate putamen, quinpirole produced a maximum inhibition of $[\mathrm{DA}]_{\max }$ of $73.2 \pm 3.5 \%$ in prenatal saline and $78.0 \pm 1.0 \%$ in prenatal cocaine-treated rats $(n=4)$. The $\log$-concentration that extrapolated to the half-maximal response $\left(\log \mathrm{EC}_{50}\right)$ was $-6.95 \pm$ $0.11(112 \mathrm{nM})$ for prenatal saline and $-6.95 \pm 0.03(112 \mathrm{nM})$ for prenatal cocaine-treated rats. In the nucleus accumbens, quinpirole produced a maximum inhibition of $[\mathrm{DA}]_{\max }$ of $83.4 \pm 3.4 \%$ in prenatal saline and $87.6 \pm 0.9 \%$ in prenatal cocaine-treated rats $(n=4)$. The $\log \mathrm{EC}_{50}$ was $-7.63 \pm 0.11(23.7 \mathrm{nM})$ for prenatal saline and $-7.64 \pm 0.03(23.1 \mathrm{nM})$ for prenatal cocaine-treated rats. Quinpirole was highly effective at inhibiting dopamine release $\left(F_{4,30}=54.13, P<0.0001\right.$, caudate putamen; $F_{4,30}=84.16, P<0.0001$, nucleus accumbens), but prenatal treatment had no significant effect $\left(F_{1,30}=0.03, P>0.05\right.$, caudate putamen; $F_{1,30}=0.10, P>0.05$, nucleus accumbens) or interaction $\left(F_{4,30}=0.30, P>0.05\right.$, caudate putamen; $F_{4,30}=0.57, P>0.05$, nucleus accumbens) with this. In addition, there were no significant differences between treatment groups in the extrapolated maximal response for quinpirole or its $\mathrm{EC}_{50}$ in either region $(P>0.05$, unpaired $t$-test).

\subsection{Tissue content}

Tissue levels of dopamine and its metabolites DOPAC and HVA were measured in the caudate putamen and nucleus accumbens (Fig. 4).

In the caudate putamen, there was $93.7 \pm 1.8 \mathrm{pmol} / \mathrm{mg}$ of dopamine, $10.8 \pm 0.5 \mathrm{pmol} / \mathrm{mg}$ of DOPAC and $3.40 \pm 0.22 \mathrm{pmol} / \mathrm{mg}$ of HVA in prenatal saline and $69.0 \pm 8.2 \mathrm{pmol} / \mathrm{mg}$ of dopamine, $8.27 \pm 0.95 \mathrm{pmol} / \mathrm{mg}$ of DOPAC and $2.69 \pm 0.28 \mathrm{pmol} / \mathrm{mg}$ of HVA in prenatal cocaine-treated rats $(n=5)$. These levels of dopamine and DOPAC were significantly lower in prenatal cocaine-treated rats $(P<0.05)$, but there was no significant difference for HVA $(P>0.05)$.

In the nucleus accumbens, there was $54.5 \pm 0.47 \mathrm{pmol} / \mathrm{mg}$ of dopamine, $12.0 \pm 1.6 \mathrm{pmol} /$ $\mathrm{mg}$ of DOPAC and $2.80 \pm 0.16 \mathrm{pmol} / \mathrm{mg}$ of HVA in prenatal saline and $43.8 \pm 4.6 \mathrm{pmol} / \mathrm{mg}$ of dopamine, $8.63 \pm 0.77 \mathrm{pmol} / \mathrm{mg}$ of DOPAC and $2.03 \pm 0.33 \mathrm{pmol} / \mathrm{mg}$ of HVA in prenatal cocaine-treated rats $(n=5)$. There was no significant difference in these levels between prenatal treatment groups $(P>0.05)$.

Tissue levels were also measured in the prefrontal cortex where there was no significant difference in dopamine (DOPAC and HVA were undetectable) between the prenatal treatment groups $(P>0.05$; data not shown). In addition, levels of serotonin, 5hyroxyindolacetic acid and norepinephrine were measured and were no different between treatment groups in any of the nuclei $(P>0.05$; data not shown).

\section{Discussion}

In this study we tested the hypothesis that prenatal cocaine exposure modifies presynaptic dopamine function in adult male rats. The dopaminergic response to single pulse electrical stimulation was no different between prenatal treatment groups in either the caudate putamen or the nucleus accumbens. The peak amplitude is determined by the balance between release and uptake, and therefore this balance does not appear to be altered by prenatal cocaine exposure. This could be either because release and uptake are both unaltered or they have changed in parallel. For stimulation trains, the dependence of 
$[D A]_{\max }$ on uptake is greater than for single pulse stimulations. This is because in addition to affecting the amplitude of the individual peak response for each impulse uptake exclusively controls extracellular dopamine concentration between pulses, and therefore determines the extent of summation of the response to individual pulses. For stimulus trains, there was also no difference in $[\mathrm{DA}]_{\max }$ between prenatal treatment groups. Together these data suggest that there is not a parallel change in release and uptake, and that neither parameter is altered by prenatal cocaine treatment. Furthermore, when evoked responses were modeled, release $\left([\mathrm{DA}]_{\mathrm{p}}\right)$ and uptake $\left(K_{\mathrm{m}}\right.$ and $\left.V_{\max }\right)$ parameters were also no different in rats that received prenatal cocaine or saline, further corroborating that release and uptake are unaltered. The release parameter measured here is evoked and therefore solely reflects presynaptic mechanisms rather than incorporating effects of action potential traffic. This parameter is controlled by the amount of dopamine in the synaptic vesicles, influenced by dopamine biosynthesis and the vesicular monoamine transporter, and the number of vesicles released per impulse, influenced by vesicle trafficking mechanisms and exocytosis. The present data suggest that all of these mechanisms remain intact in male adult rats that were prenatally exposed to cocaine.

The effect of acute cocaine challenge was not different between prenatal treatment groups in either the caudate putamen or the nucleus accumbens. This once again indicates that uptake is normal following prenatal cocaine exposure, and also suggests that the dopamine transporter does not have altered sensitivity to cocaine. Interestingly, in a whole animal study, the dopaminergic response to systemic cocaine challenge was enhanced in the nucleus accumbens of adult rats that were exposed to cocaine in utero [15]. The brain slice preparation is reductionist: the isolated dopaminergic terminals are devoid of impulse traffic and control by tonic releasing agents [8] such as glutamate, narrowing the number of pharmacological targets. Since this reductionism removes sensitization to acute challenge with cocaine, it alludes to targets of the sensitization. The key pharmacological target for cocaine regulating the evoked extracellular dopamine response in the brain slice preparation is the dopamine transporter on dopaminergic terminals. The present data clearly demonstrates that this is not the target of the sensitization seen by others. Thus, it must be regulated at another level such as dopaminergic cell firing and/or serotonergic mechanisms.

Prenatal exposure to cocaine also did not alter the action of the D2-like agonist, quinpirole on dopamine release in the male adult. This suggests that release- and synthesis regulating autoreceptors function normally, and are not altered in number by prenatal cocaine treatment. Consistent with this, it was reported that neither D2 binding nor mRNA levels are altered in the striatum of adults rats that were prenatally exposed to cocaine [31]. However, another study observed a $20 \%$ decrease in the maximum ligand binding at D2 receptors for 180 day old, prenatal cocaine-exposed male [9]. In light of our findings, it would seem that any effect must be limited to changes in a subpopulation of postsynaptic D2 receptors, (since the presynaptic D2 receptors remain functionally intact).

In rats that received cocaine prenatally, the content of dopamine was significantly reduced in the caudate putamen, with a similar, but non-significant trend in the nucleus accumbens. This is consistent with reduced dopamine response to amphetamine challenge beyond postnatal day 80 as reported by others in prenatal cocaine-exposed male rats $[7,26,30]$. Terminal dopamine content could be decreased if its metabolism by monoamine oxidase in the cytosol was increased, but since levels of DOPAC (the metabolic product) were also decreased, this is unlikely to be the case. Dopamine levels could also be reduced if its utilization was increased. We have shown in the present study that release mechanisms function normally in adult rats prenatally exposed to cocaine. Therefore a net increase in release could only come about by an increase in the rate of its triggering i.e. increased impulse traffic to the terminal and/or tone of releasing agents such as glutamate. However, if 
this were the case, there would be an increase in the outflow of dopamine to the extracellular space. Keller and colleagues $[15,16]$ have shown that extracellular levels of adult rats prenatally exposed to cocaine are normal in both the caudate putamen [16] and the nucleus accumbens [15]. These measurements provide information on the net balance between the maintained outflow of dopamine (release) and its clearance. The predominant mechanism for clearance of extracellular dopamine is uptake into dopaminergic terminals via the dopamine transporter [2,5], and in the present study, we demonstrated that this is unaltered. Therefore it follows that the maintained release must also be unchanged in rats prenatally exposed to cocaine. Uptake of dopamine into terminals also provides a source of intracellular dopamine, and since it is unaltered, this also cannot account for the decreased dopamine levels. Dopamine biosynthesis could be reduced, but this would cause a decrease in electrically evoked dopamine release that was not observed in the present study. Furthermore, since the terminal operates at equilibrium, the production of dopamine must balance the consumption. The data presented here and in the literature suggest that the consumption of dopamine is not altered suggesting that dopamine synthesis should also be unaltered. Since the content of dopamine in the terminals mainly reflects storage pools of dopamine [19], this leaves the possibility that the amount of stored dopamine (bound to the cytoskeleton) is decreased. However, this effect should not alter dopaminergic function other than during extreme challenge (e.g. with amphetamine) or dopamine depletion.

In summary, we report that presynaptic dopaminergic function remains largely intact in adult, male rats that were prenatally exposed to cocaine. The ability for terminals in the caudate putamen and nucleus accumbens to release and regulate dopamine is unaltered. However the tissue content of dopamine in the caudate putamen was decreased, representing a diminution in the dopamine storage pool. We conclude that behavioral abnormalities observed in adults that were exposed to cocaine in utero are not mediated through presynaptic dopaminergic mechanisms in mesolimbic or mesostriatal neurons. These effects possibly arise because of changes in the serotonergic or noradrenergic systems following prenatal cocaine exposure.

\section{Acknowledgments}

The authors would like to acknowledge Dr Joshua Joseph for technical assistance. This work was supported by NIDA DA/AA13362, DA13283-01A1 (JMJ), MH33127 (JAL) and NINDS NS15841 (RMW).

\section{References}

1. Alger, BE.; Dhanjal, SS.; Dingledine, R.; Garthwaite, J.; Henderson, G.; King, GL.; Lipton, P.; North, A.; Schwartzkroin, PA.; Sears, TA.; Segal, M.; Whittingham, TS.; Williams, J. Brain slice methods. In: Dingledine, R., editor. Brain Slices. New York: Plenum Press; 1984. p. 381-437.

2. Ewing AG, Wightman RM. Monitoring the stimulated release of dopamine with in vivo voltammetry. II: Clearance of released dopamine from extracellular fluid. J. Neurochem. 1984; 43:570-577. [PubMed: 6736966]

3. Friedman E, Wang HY. Prenatal cocaine exposure alters signal transduction in the brain D1 dopamine receptor system. Ann. NY Acad. Sci. 1998; 846:238-247. [PubMed: 9668411]

4. Gifford AN, Johnson KM. Comparison of the role of local anesthetic properties with dopamine uptake blockade in the inhibition of striatal and nucleus accumbens $\left[{ }^{3} \mathrm{H}\right]$ acetylcholine release by cocaine. J. Pharmacol. Exp. Ther. 1992; 263:757-761. [PubMed: 1359115]

5. Giros B, Jaber M, Jones SR, Wightman RM, Caron MG. Hyperlocomotion and indifference to cocaine and amphetamine in mice lacking the dopamine transporter. Nature. 1996; 379:606-612. [PubMed: 8628395]

6. Giustino A, Cuomo V, Marsden CA. Maternal cocaine exposure alters mesolimbic dopaminergic function in rat offspring. Eur. J. Pharmacol. 1998; 345:175-180. [PubMed: 9600634] 
7. Glatt SJ, Bolanos CA, Trksak GH, Crowder-Dupont C, Jackson D. Prenatal cocaine exposure alters behavioral and neurochemical sensitization to amphetamine in adult rats. Neuropharmacology. 2000; 39:599-610. [PubMed: 10728881]

8. Grace AA. Phasic versus tonic dopamine release and the modulation of dopamine system responsivity: a hypothesis for the etiology of schizophrenia. Neuroscience. 1991; 41:1-24. [PubMed: 1676137]

9. Henderson MG, McConnaughey MM, McMillen BA. Long-term consequences of prenatal exposure to cocaine or related drugs: effects on rat brain monoaminergic receptors. Brain Res. Bull. 1991; 26:941-945. [PubMed: 1657320]

10. Johns JM, Means MJ, Bass EW, Means LW, Zimmerman LI, McMillen BA. Prenatal exposure to cocaine: effects on aggression in Sprague-Dawley rats. Dev. Psychobiol. 1994; 27:227-239. [PubMed: 7913451]

11. Johns JM, Noonan LR. Prenatal cocaine exposure affects social behavior in Sprague-Dawley rats. Neurotoxicol. Teratol. 1995; 17:569-576. [PubMed: 8552003]

12. Jones SR, Gainetdinov RR, Jaber M, Giros B, Wightman RM, Caron MG. Profound neuronal plasticity in response to inactivation of the dopamine transporter. Proc. Natl. Acad. Sci. USA. 1998; 95:4029-4034. [PubMed: 9520487]

13. Jones SR, Garris PA, Wightman RM. Different effects of cocaine and nomifensine on dopamine uptake in the caudate putamen and nucleus accumbens. J. Pharmacol. Exp. Ther. 1995; 274:396403. [PubMed: 7616424]

14. Kato T, Dong B, Ishii K, Kinemuchi H. Brain dialysis: in vivo metabolism of dopamine and serotonin by monoamine oxidase A but not B in the striatum of unrestrained rats. J. Neurochem. 1986; 46:1277-1282. [PubMed: 2419508]

15. Keller RW Jr, Johnson KS, Snyder-Keller AM, Carlson JN, Glick SD. Effects of prenatal cocaine exposure on the mesocorticolimbic dopamine system: an in vivo microdialysis study in the rat. Brain Res. 1996; 742:71-79. [PubMed: 9117423]

16. Keller RW Jr, Maisonneuve IM, Nuccio DM, Carlson JN, Glick SD. Effects of prenatal cocaine exposure on the nigrostriatal dopamine system: an in vivo microdialysis study in the rat. Brain Res. 1994; 634:266-274. [PubMed: 8131076]

17. Kennedy RT, Jones SR, Wightman RM. Dynamic observation of dopamine autoreceptor effects in rat striatal slices. J. Neurochem. 1992; 59:449-455. [PubMed: 1352798]

18. Kennedy RT, Jones SR, Wightman RM. Simultaneous measurement of oxygen and dopamine: coupling of oxygen consumption and neurotransmission. Neuroscience. 1992; 47:603-612. [PubMed: 1316568]

19. Kuhr WG, Bigelow JC, Wightman RM. In vivo comparison of the regulation of releasable dopamine in the caudate nucleus and the nucleus accumbens of the rat brain. J. Neurosci. 1986; 6:974-982. [PubMed: 3486259]

20. Lipton JW, Vu TQ, Ling Z, Gyawali S, Mayer JR, Carvey PM. Prenatal cocaine exposure induces an attenuation of uterine blood flow in the rat. Neurotoxicol. Teratol. 2002; 24:143-148. [PubMed: 11943502]

21. Lubin DA, Meter KE, Walker CH, Johns JM. Effects of chronic cocaine administration on aggressive behavior in virgin female rats. Prog. Neuro-Psychopharmacol. Biol. Psychiatry. 2001; 25:1403-1420.

22. Lubin DA, Meter KE, Walker CH, Johns JM. Dose related effects of chronic gestational cocaine treatment on maternal aggression in rats on postpartum days 2, 3 and 5. Prog. Neuro-Psychopharmacol. Biol. Psychiatry. 2001; 25:1421-1433.

23. Minabe Y, Ashby CR Jr, Heyser C, Spear LP, Wang RY. The effects of prenatal cocaine exposure on spontaneously active mid-brain dopamine neurons in adult male offspring: an electrophysiological study. Brain Res. 1992; 586:152-156. [PubMed: 1511345]

24. Overstreet DH, Moy SS, Lubin DA, Gause LR, Lieberman JA, Johns JM. Enduring effects of prenatal cocaine administration on emotional behavior in rats. Physiol. Behav. 2000; 70:149-156. [PubMed: 10978490] 
25. Parsons TD, Coorssen JR, Horstmann H, Lee AK, Tse FW, Almers W. The last seconds in the life of a secretory vesicle. Cold Spring Harbor Symp. Quant. Biol. 1995; 60:389-396. [PubMed: 8824412]

26. Peris J, Coleman-Hardee M, Millard WJ. Cocaine in utero enhances the behavioral response to cocaine in adult rats. Pharmacol. Biochem. Behav. 1992; 42:509-515. [PubMed: 1409782]

27. Phillips PEM, Hancock PJ, Stamford JA. Time window of autoreceptor-mediated inhibition of limbic and striatal dopamine release. Synapse. 2002; 44:15-22. [PubMed: 11842442]

28. Pieribone VA, Shupliakov O, Brodin L, Hilfiker-Rothenfluh S, Czernik AJ, Greengard P. Distinct pools of synaptic vesicles in neurotransmitter release. Nature. 1995; 375:493-497. [PubMed: 7777058]

29. Ritz MC, Cone EJ, Kuhar MJ. Cocaine inhibition of ligand binding at dopamine, norepinephrine and serotonin transporters: a structure-activity study. Life Sci. 1990; 46:635-645. [PubMed: 2308472]

30. Simansky KJ, Kachelries WJ. Prenatal exposure to cocaine selectively disrupts motor responding to D-amphetamine in young and mature rabbits. Neuropharmacology. 1996; 35:71-78. [PubMed: 8684599]

31. Stadlin A, Choi HL, Tsim KW, Tsang D. Prenatal cocaine exposure revealed minimal postnatal changes in rat striatal dopamine D2 receptor sites and mRNA levels in the offspring. Mol. Neurobiol. 1995; 11:67-76. [PubMed: 8561969]

32. Valtorta F, Benfenati F, Greengard P. Structure and function of the synapsins. J. Biol. Chem. 1992; 267:7195-7198. [PubMed: 1559963]

33. Wightman RM, Amatore C, Engstrom RC, Hale PD, Kristensen EW, Kuhr WG, May LJ. Realtime characterization of dopamine overflow and uptake in the rat striatum. Neuroscience. 1988; 25:513-523. [PubMed: 3399057]

34. Wood RD, Spear LP. Prenatal cocaine alters social competition of infant, adolescent, and adult rats. Behav. Neurosci. 1998; 112:419-431. [PubMed: 9588488] 

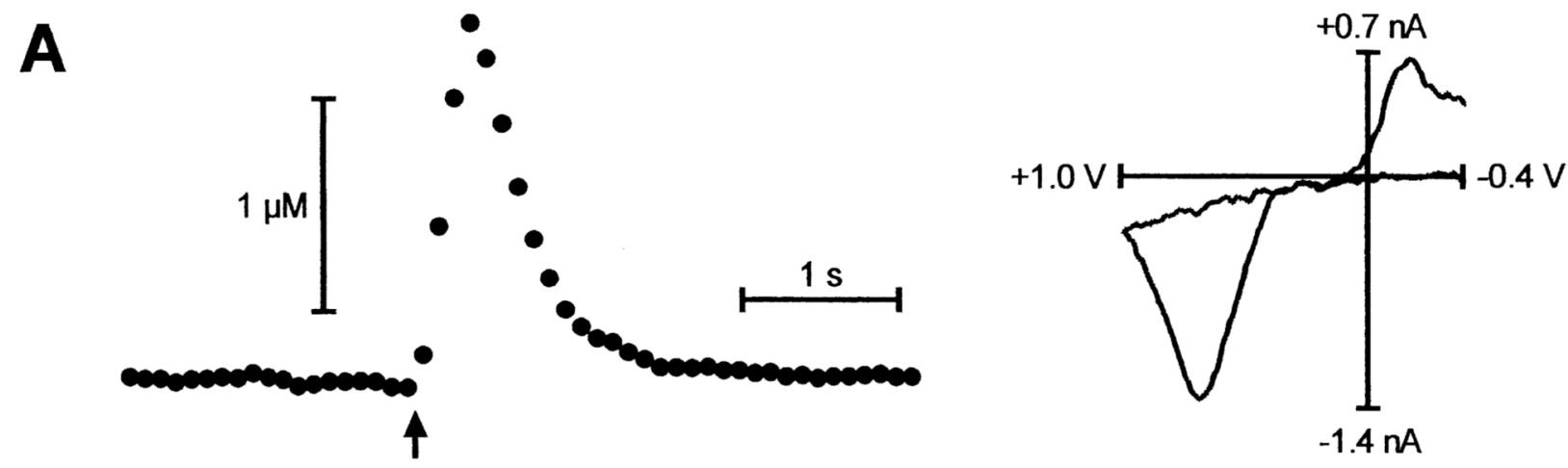

B

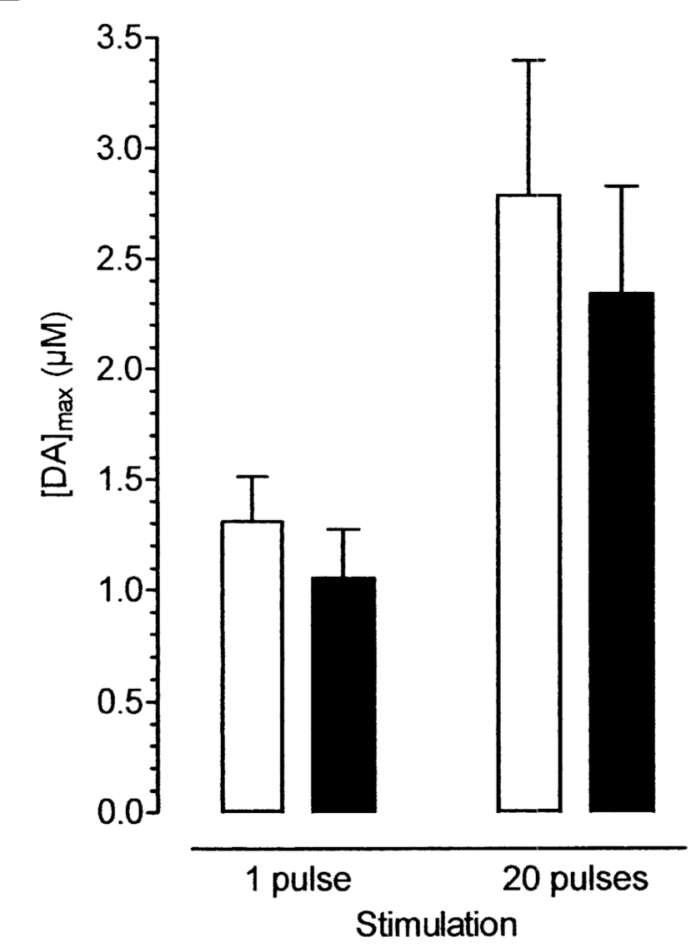

Fig. 1.
Nucleus Accumbens

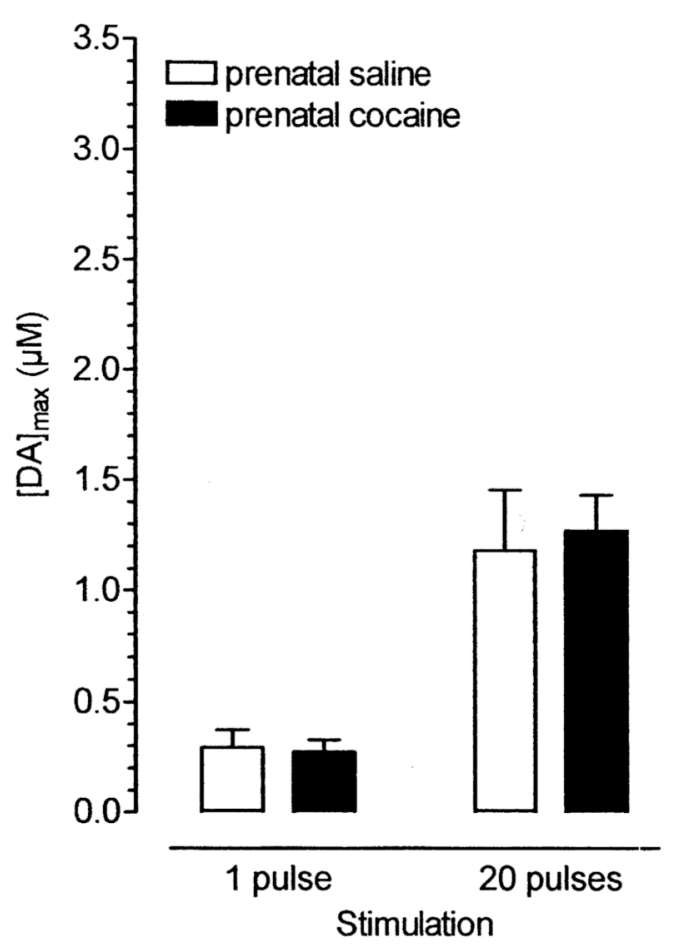

Dopamine release evoked by electrical stimulation. (A) Representative neurochemical responses in the dorsolateral caudate putamen to local electrical stimulation (single biphasic pulse, $\pm 300 \mu \mathrm{A}, 2 \mathrm{~ms}$ /phase). Following the stimulation (indicated by the arrow), there is a rise in extracellular dopamine, followed by a decrease back to baseline. Each point represents a measurement of dopamine concentration from one voltammetric scan taken every $100 \mathrm{~ms}$. The right panel shows a background-subtracted cyclic voltammogram taken at the peak response to the stimulus. The $x$-axis of this represents the applied potential (vs. $\mathrm{Ag} / \mathrm{AgCl}$ ) and the $y$-axis represents the faradaic current yielded during a single voltammetric scan. The voltammogram provides chemical information on the analyte: it has an oxidation 
peak (negative current) at applied potential $+0.6 \mathrm{~V}$ and reduction peak (positive current) at $-0.2 \mathrm{~V}$, characteristic of dopamine. (B) The peak extracellular dopamine concentration $\left([D A]_{\max }\right)$ following a single electrical pulse or a train of twenty pulses $(50 \mathrm{~Hz})$ in the dorsolateral caudate putamen (left) or the core of the nucleus accumbens (right). Responses for prenatal cocaine-treated rats are represented by the solid bars and for saline-treated rats by the open bars. Prenatal treatment with cocaine did not alter the responses to electrical stimulation (caudate putamen: $F_{1,56}=0.05, P>0.05$; nucleus accumbens: $F_{1,43}=0.11, P>$ 0.05 ; two-way analysis of variance, $n=12-18$ ). 


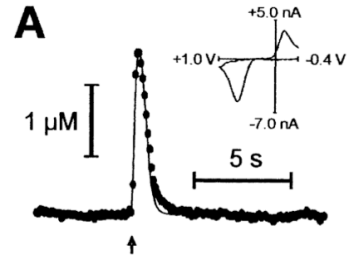

0

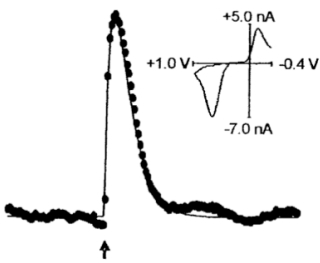

1

Cocaine $(\mu \mathrm{M})$

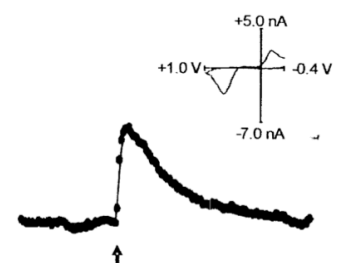

10
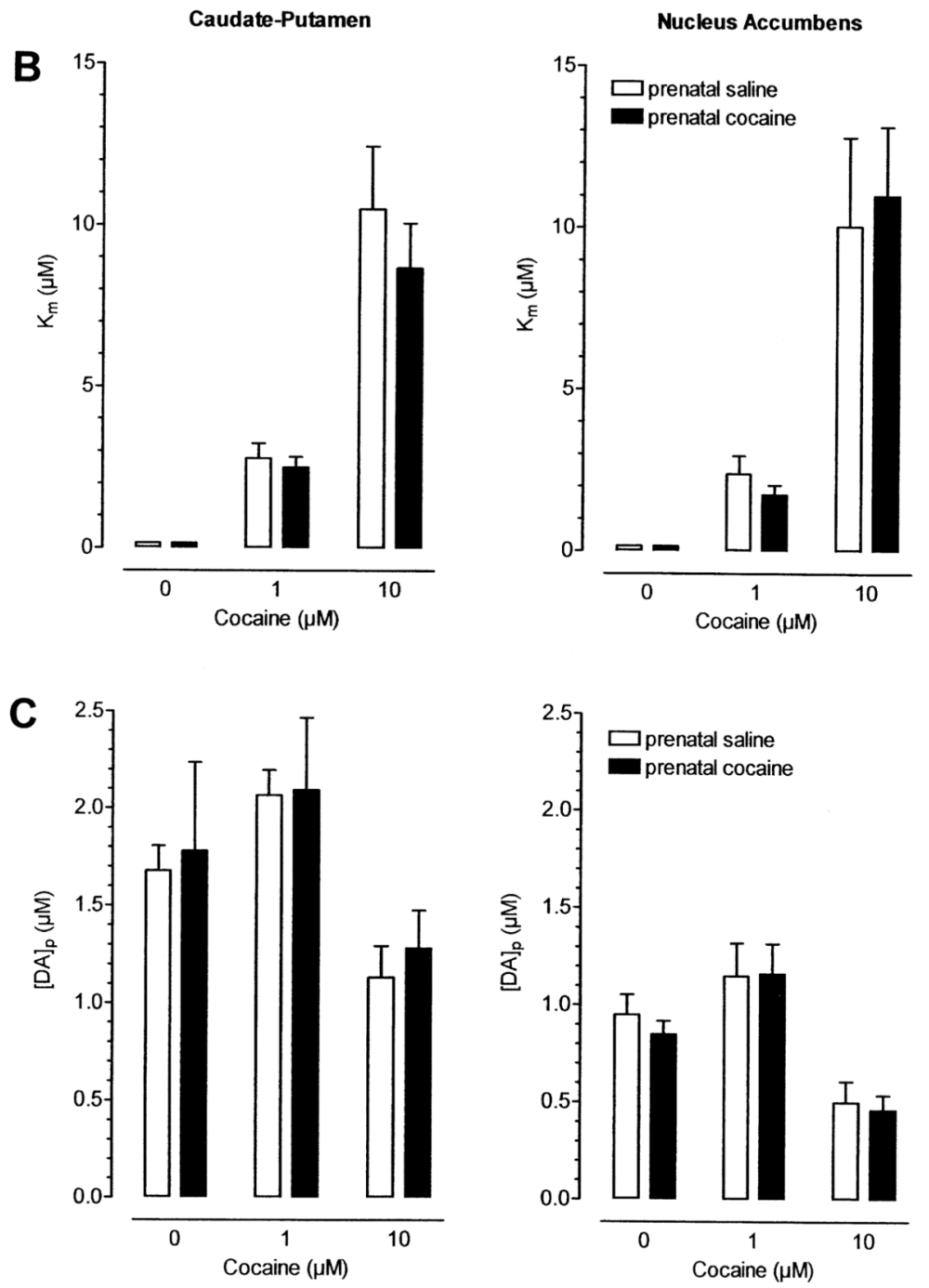

Fig. 2.

Effect of acute cocaine treatment. (A) Representative responses to 0- (left), 1- (middle) or $10-\mu \mathrm{M}$ (right) cocaine in the dorsolateral caudate putamen. Following electrical stimulation (single biphasic pulse, $\pm 300 \mu \mathrm{A}, 2 \mathrm{~ms}$ / phase; indicated by the arrow), there is a rise in extracellular dopamine, followed by a decrease back to baseline. Each point represents a measurement of dopamine concentration from one voltammetric scan taken every $100 \mathrm{~ms}$. The solid lines are fitted kinetic analyses of the responses. The insets show backgroundsubtracted cyclic voltammograms taken at the peak response to the stimulus. The $x$-axis of this represents the applied potential ( $\mathrm{vs} \mathrm{Ag} / \mathrm{AgCl})$ and the $y$-axis represents the faradaic current yielded during a single voltammetric scan. The voltammogram provides chemical 
information on the analyte: it has an oxidation peak (negative current) at applied potential $+0.6 \mathrm{~V}$ and reduction peak (positive current) at $-0.2 \mathrm{~V}$, characteristic of dopamine. (B) The effect of cocaine on the apparent Michaelis-Menten rate constant for uptake $\left(K_{\mathrm{m}}\right)$ in the dorsolateral caudate putamen (left) and the core of the nucleus accumbens (right). Responses for prenatal cocaine-treated rats are represented by the solid bars and for saline-treated rats by the open bars. Prenatal treatment with cocaine did not alter the acute effects of cocaine on $K_{\mathrm{m}}$ (caudate putamen: $F_{2,9}=0.46, P>0.05$; nucleus accumbens: $F_{2,9}=0.13, P>0.05$; twoway analysis of variance, $n=4)$. (C) The effect of cocaine on the change in dopamine concentration at the electrode produced by each stimulus pulse $\left([\mathrm{DA}]_{\mathrm{p}}\right)$ in the dorsolateral caudate putamen (left) and the core of the nucleus accumbens (right). Responses for prenatal cocaine-treated rats are represented by the solid bars and for saline-treated rats by the open bars. Prenatal treatment with cocaine did not alter the acute effects of cocaine on $[\mathrm{DA}]_{\mathrm{p}}$ (caudate putamen: $F_{2,9}=0.04, P>0.05$; nucleus accumbens: $F_{2,9}=0.11, P>0.05$; two-way analysis of variance, $n=4)$. 


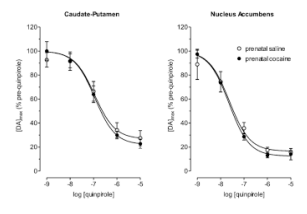

Fig. 3.

Autoreceptor function. The graphs show cumulative semilog plots of the effect of quinpirole on the peak extracellular dopamine concentration $\left([\mathrm{DA}]_{\max }\right.$ ) following a single-pulse electrical stimulation (biphasic pulse, $\pm 300 \mu \mathrm{A}, 2 \mathrm{~ms} /$ phase) in the caudate putamen (left) or the core of the nucleus accumbens (right). Responses for prenatal cocaine-treated rats are represented by the solid symbols and for saline-treated rats by the open symbols. The lines are best-fit sigmoid curves $\left(R^{2}=0.99\right)$. Prenatal treatment with cocaine did not alter the effect of quinpirole on dopamine inhibition (caudate putamen: $F_{4,30}=0.30, P>0.05$; nucleus accumbens: $F_{4,30}=0.57, P>0.05$; two-way analysis of variance, $\left.n=4\right)$. 
Caudate-Putamen

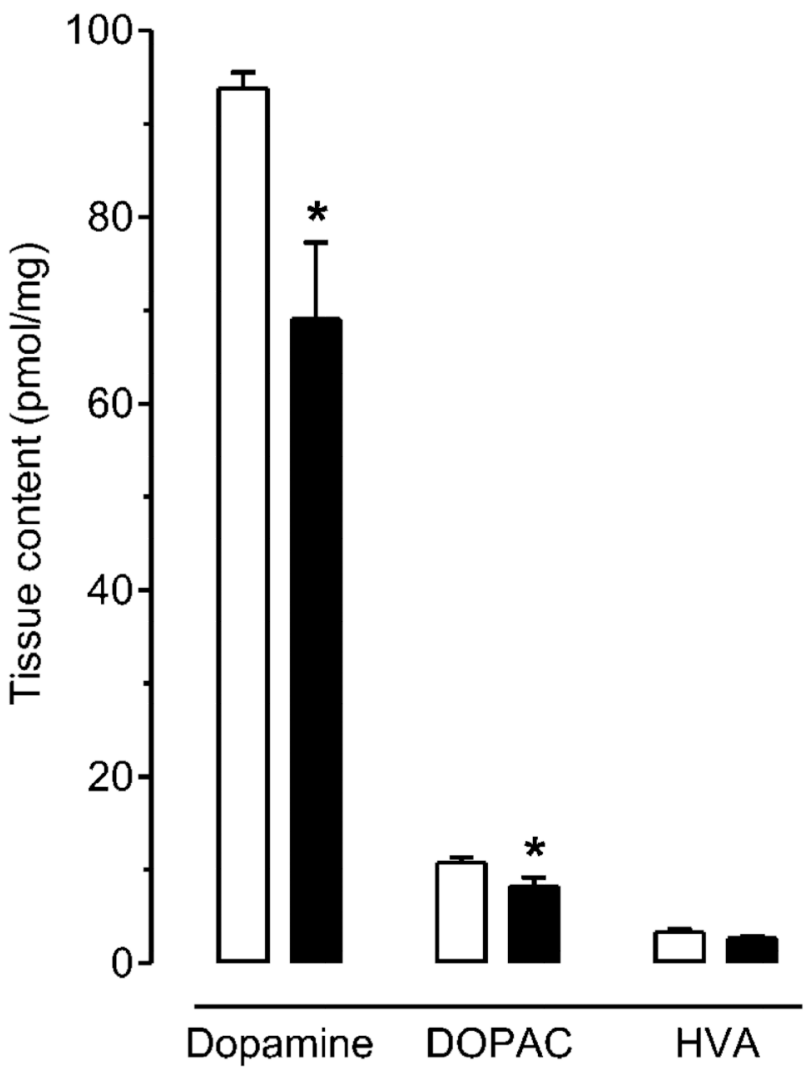

Fig. 4.
Nucleus Accumbens

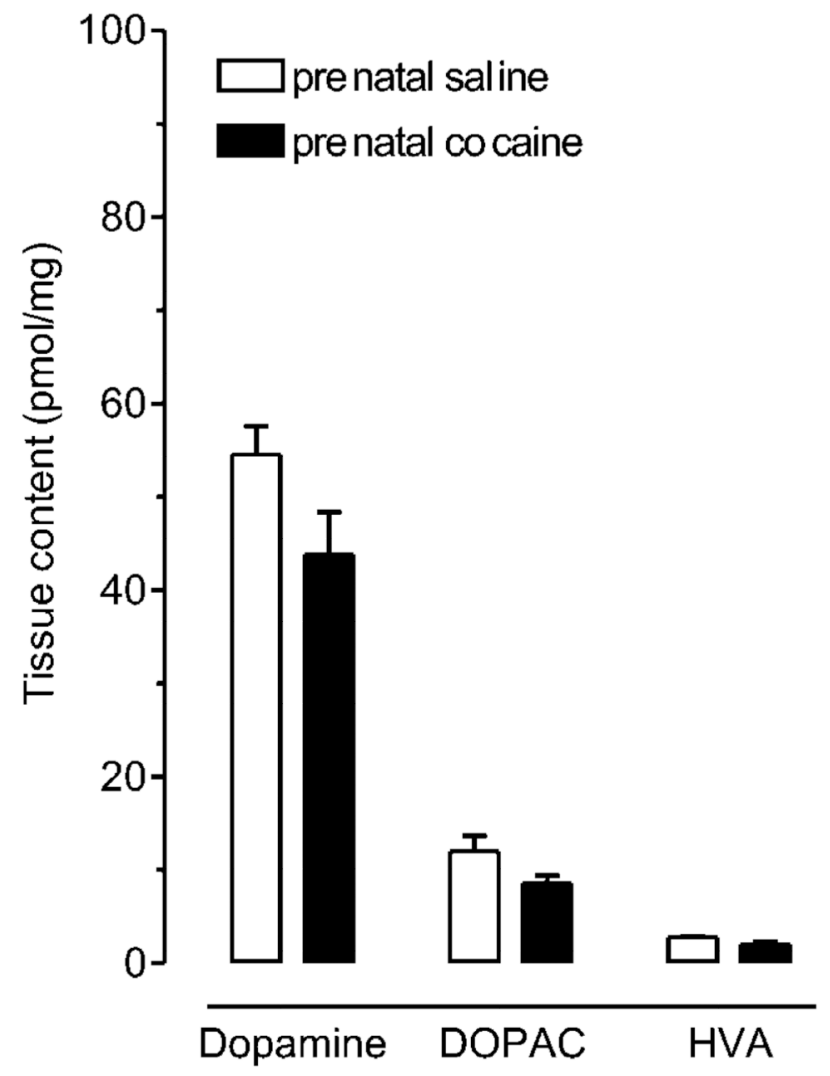

Tissue content of dopamine, 3,4-dihyroxyphenylacetic acid (DOPAC) and homovanillic acid (HVA) in the caudate putamen (left) and the core of the nucleus accumbens (right). Levels for prenatal cocaine-treated rats are represented by the solid bars and for saline-treated rats by the open bars. $* P<0.05$ vs. saline-treated control, unpaired $t$-test $(n=5)$. 